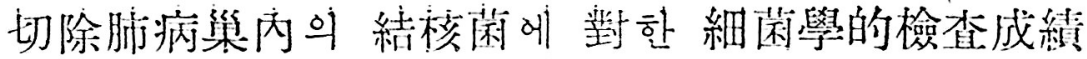

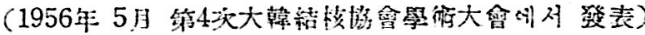

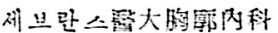 \\ 金起鎬}

緒論

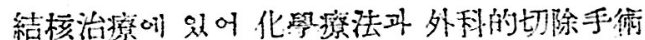

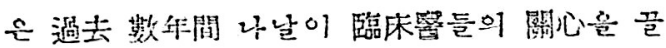

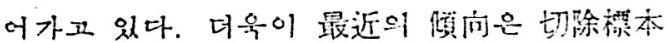

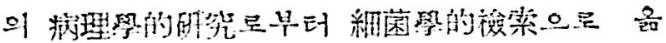
겨가는 感이 있흔데 特黑한 所見온 抗結核

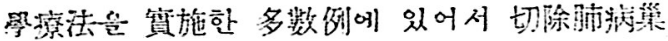

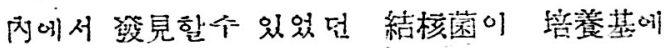

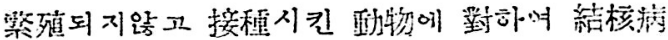
춘을 이르키기 않는다는 것이다.

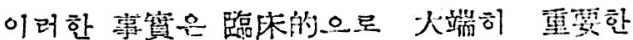

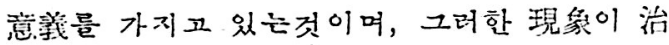

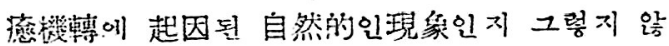
으면 化學瘵法의 直接的인 影響으로 오는것인 기 然明할 必要가 있춘것이다.

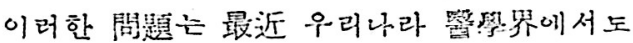
多大한 關心이 集中되어 이미 昨作6月 符 2 回

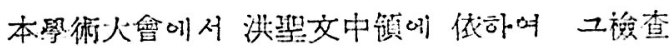

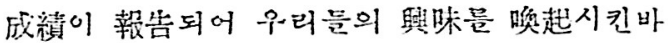

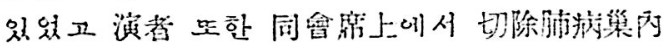

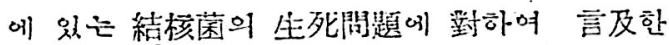
바 힜었다."

이번이 發麦하는 本報告는 演者가 Newy-

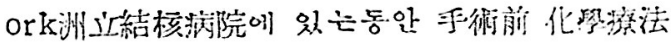

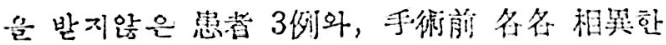

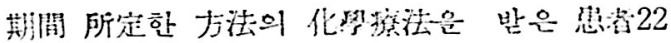

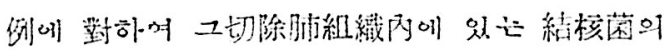

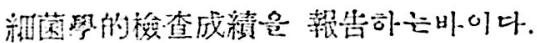

\section{實驗方法}

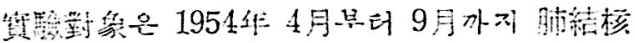

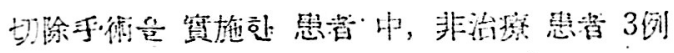

를 除外한 23名이서 얻은 切除組瀻標本 38個에 對하며 黛施하였다. 貿驗한 標本은 部分的인

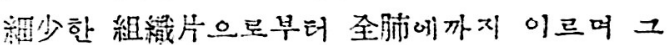

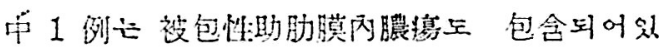
다.

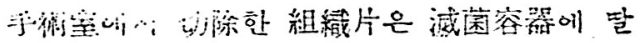

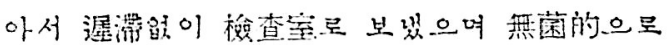
虔瑟하엿.다.

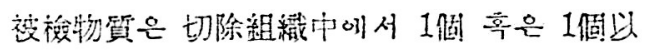
上, 손에 만저지는대로 游樂部分을 切取하였

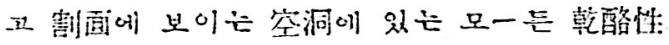
特質은 Curret.르 긁어서 少量의 Saline이 들 어있는 試䮦管에 넣어 큰 部分이 粉粹되어 均 等한 浮遊液이 되로록 갈 振落하였다. 그中

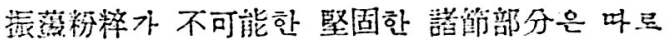
刑鉢이다 넣어 充分히 磨隇한 後에 Saline에 浮遊시켜 處㻇하엿.다.

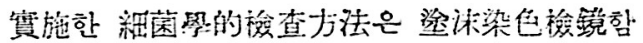

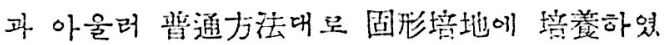
으며 또한 浮遊液의 1乃至 2cc를 煡康한 guinea pig의 鼠湤部에 it:期하였.다.

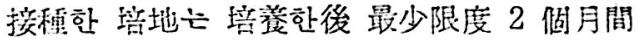

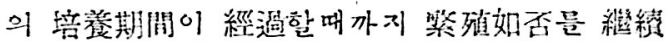
期察하였으머, 一㑔接種한 guinea pig은 生1

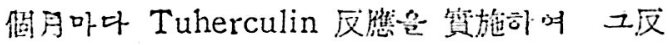

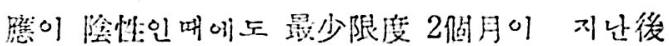
에 비로서 剖放하사였다.

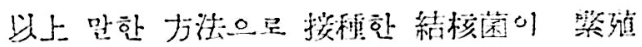

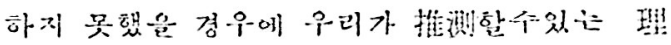

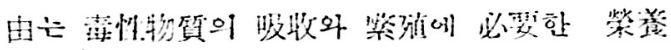

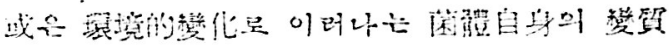
을 生琶新侎 있는것이다. 


\section{實 驗成綪}

本筫驗은 3群으로 分類하며 貿施하였는네 第一群은 16名의 屋者로 부더 切除한 25 㑑被 檢物에 對하여 質施하였다. 이 16 名의 腎者亡

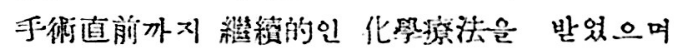

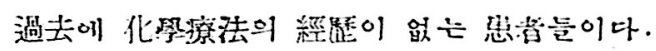
그結果는 第一表에 보츤바와 같다.

手街前喀咨襝查의 成績은 手街前4 個月間,

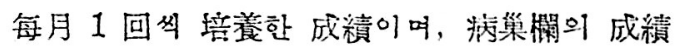

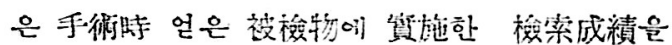
顋味한다.

第二表에 낭다난 結果는 一回达上 反復하여 一定한 期間 化學瘁法을 받은 일이 잇으며, 中

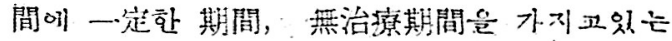
患者 6名에게서 얻은 13염被檢物 에 對한 成續 이나.

第三表에서든 全然 化學療法을 받은 일이엾

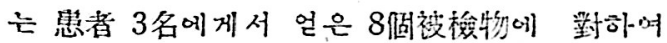
垻施한 成績이나.

第一表에서 보는바와같이 初施治療群의

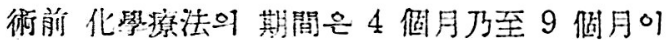

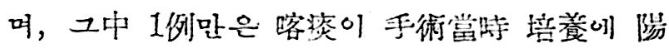
ㄴㄴ으을 나타 났다.

또한 우리가 注目한 事賔은 直接叙洙에 있 어서 手術前 16例中 16番을 除外한 15例가 梌

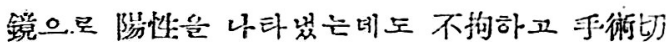
㭙切除한 被檢物의 培養训 있어서는 오직 4 例만이 陵性으로 나타났다는 것이다.

第二表에서 보는.再施治療群에 있어서의 結 果云 初施治療群과 比敦하기 어는 多少 그例歡 가 적은 感이 없거 않아 있다.

第一变

易施化盆治群

\begin{tabular}{|c|c|c|c|c|c|c|c|c|}
\hline \multirow[b]{2}{*}{ - } & \multicolumn{2}{|l|}{ 海 $_{1}^{x}$} & \multicolumn{2}{|r|}{ 设 } & \multirow{2}{*}{ 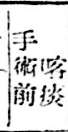 } & \multicolumn{3}{|c|}{ 切除花 14} \\
\hline & $\begin{array}{l}\text { 手污前 } \\
\text { 如 间 }\end{array}$ & $\left|\begin{array}{l}-\overline{S M} \\
\mathrm{GM}\end{array}\right|$ & $\begin{array}{r}\mathrm{H} \\
\mathrm{PAS} \\
\mathrm{GM} \\
\end{array}$ & 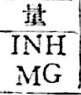 & & 婇谍 & 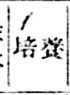 & 徒物 \\
\hline 1 & 7個月間 & 1.0 & 12 & & - & II & - & 一 \\
\hline 2 & $5 "$ & 1.0 & 12 & & - & III & - & 一 \\
\hline 3 & $5 \prime \prime$ & 0.5 & 12 & 350 & - & III & - & - \\
\hline 4 & $9 "$ & 1.0 & 12 & & - & II & - & - \\
\hline
\end{tabular}

\begin{tabular}{|c|c|c|c|c|c|c|c|c|c|}
\hline 5 & 9 & $\begin{array}{l}\| \\
.\end{array}$ & 1.0 & $12^{\prime}$ & & - & $\begin{array}{c}\text { I } \\
\text { II } \\
-\end{array}$ & -1 & $\begin{array}{l}+ \\
+ \\
+\end{array}$ \\
\hline 6 & 6 & $"$ & 0.5 & 9 & & -1 & I & - & - \\
\hline 7 & 4 & $"$ & 0.5 & 9 & & - & II & - & - \\
\hline 8 & 7 & " & & 12 & 350 & - & $\begin{array}{l}\mathrm{V} \\
-\end{array}$ & +1 & $\begin{array}{l}+ \\
+ \\
\end{array}$ \\
\hline 9 & 6 & $"$ & 0.5 & 12 & 350 & -1 & III & - & - \\
\hline 10 & 6 & $" \prime$ & $0.5^{\prime}$ & 12 & 350 & - & $\begin{array}{l}\text { II } \\
-\end{array}$ & + & $\begin{array}{l}+ \\
-\end{array}$ \\
\hline 11 & 9 & $" \prime$ & 1.0 & 12 & 350 & + & $\frac{\text { II }}{\text { II }}$ & - & $\begin{array}{l}- \\
- \\
+\end{array}$ \\
\hline 12 & 6 & $" \prime$ & 0.5 & 12 & 350 & - & $\begin{array}{c}\mathrm{V} \\
\text { III }\end{array}$ & - & - \\
\hline 13 & 4 & $\mu$ & 1.0 & 12 & & - & II & -1 & - \\
\hline 14 & 6 & $"$ & 0.5 & 12 & & -1 & II & -1 & - \\
\hline 15 & 6 & " & 0.5 & 9 & & -1 & $I$ & -1 & - \\
\hline 16 & 8 & $\|$ & 1.0 & 12 & & -1 & - & -1 & - \\
\hline
\end{tabular}

第二

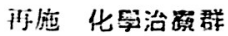

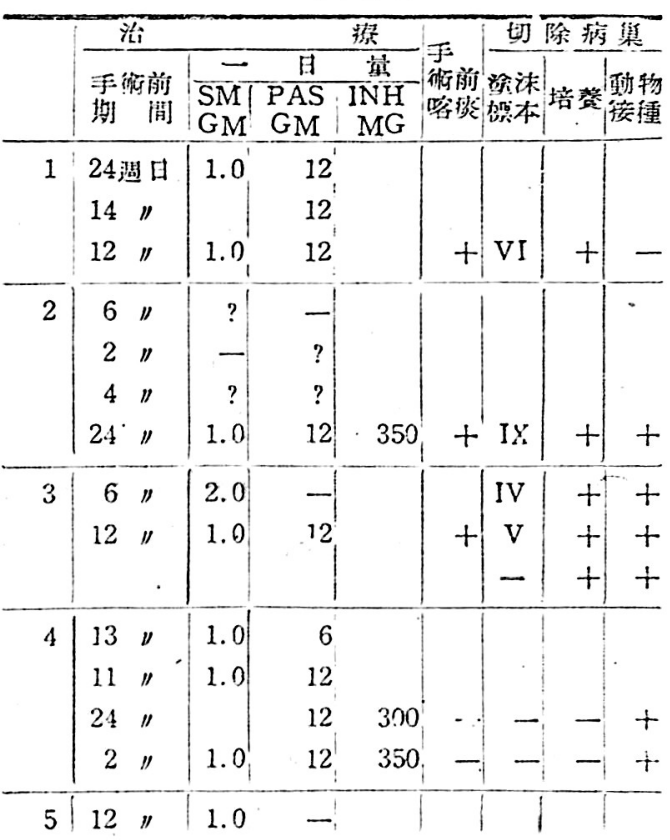




\begin{tabular}{r|rl|rr|r|r|r|r|r} 
& $4 \prime \prime$ & - & $?$ & & + & $\mathrm{V}$ & - & - \\
& $12 \prime \prime$ & 1.0 & 12 & 350 & - & $\mathrm{VI}$ & - & - \\
\hline 6 & $13 \prime \prime$ & 1.0 & 10 & & - & $\mathrm{I}$ & - & + \\
& $11 \prime \prime$ & 1.0 & 12 & & & $\mathrm{II}$ & + & + \\
$12 \prime$ & - & 12 & 350 & & - & - & + \\
& $1 \prime \prime$ & 1.0 & 12 & 350 & & - & - & + \\
\hline
\end{tabular}

第三素

非 治 䨳 群

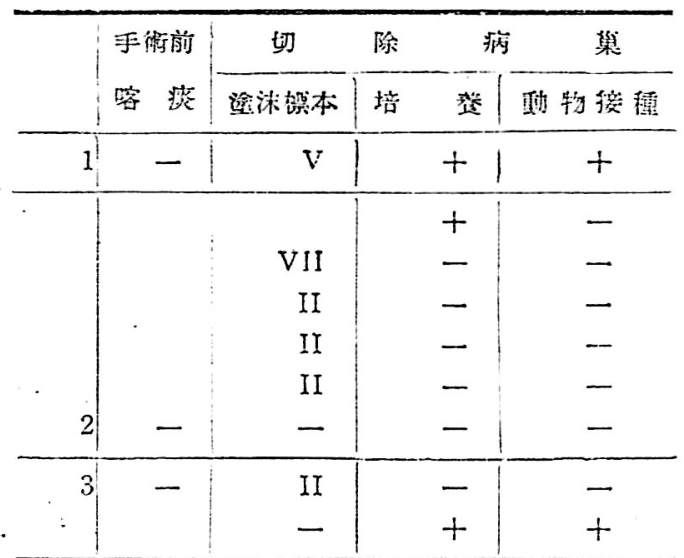

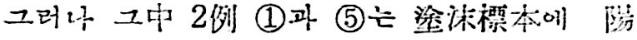

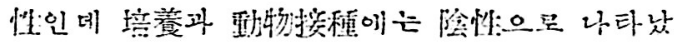
다. 다른 또 한(例 (4)에 있어시는 檢鏡베는 抗

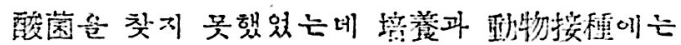
隄性으로 나타넜다.

籍三表이 있어서는 보시는바와 같이 3名 모 투 乎街前이는 아무 化學疾法을 받은적이 없.

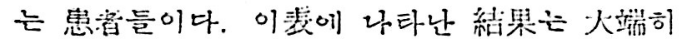

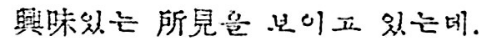

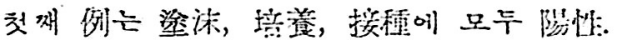

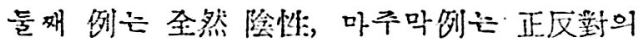

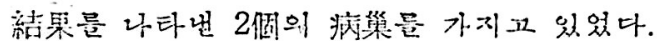

\section{考按}

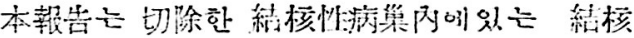

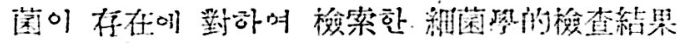
른 만하는격이다.

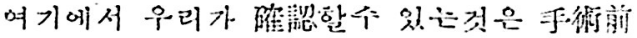

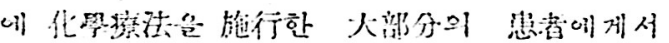

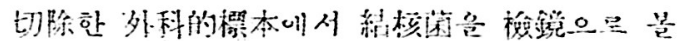

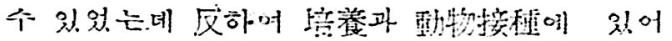

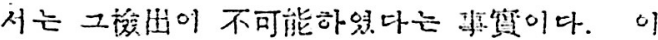

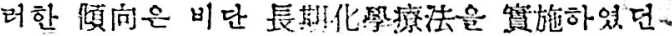
患者어게서만 볼수있었던 것이 아니라 比較的 短期閒治療를 받은 虫者에서도 볼수 있였드네

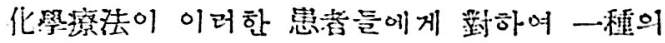
原因的要菒가 될수 있을런지는 모르나 - 便 手遇前에 化㧳源法을 받은일이 없는 2例에 있

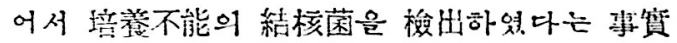
온 患学自身의 自然的인 防繁力이 依하는것ㅇ 라고 生覺해야 하는것이다. 이러한 觀點으로 本絬果를 볼때 問題되는 것은 手術前 化祭治

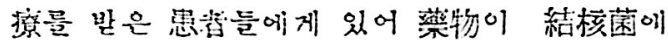
게 준 影譥이 어떠한 画으로 作朋하였 는지를 洪定하기는 大端히 어려운 䦗題라고 말하겠 다.

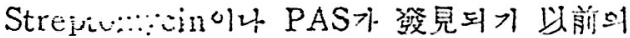

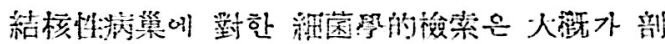

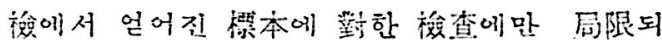

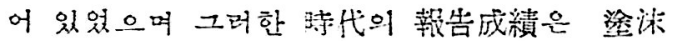

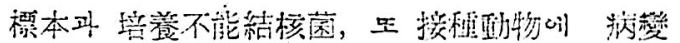

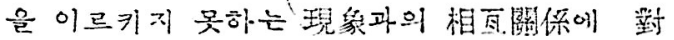

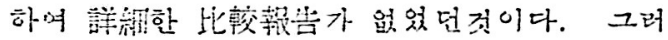

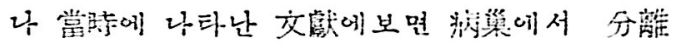

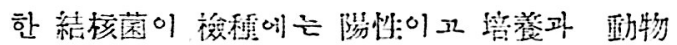
接種에 㓌性으로 나타나는 䍐臬은 結核菌의

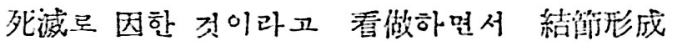

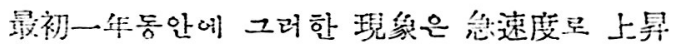
하여 結節形成後 5作 或은 그사이 될때에 는

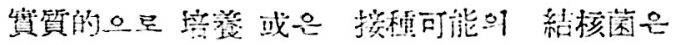
그자최를 감추게 된다고 椌明하고 있다.

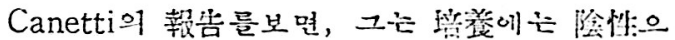

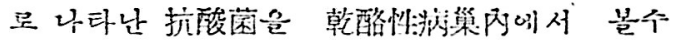

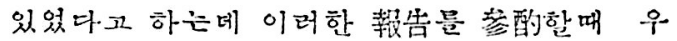

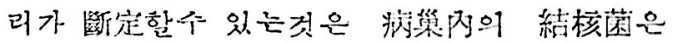
自然的인 裗轉으로도 그奖殖能力을 잃을 个가

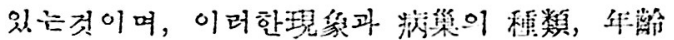

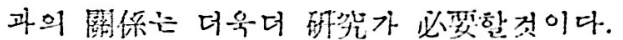

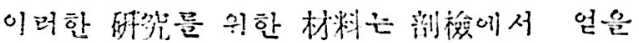

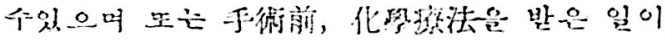

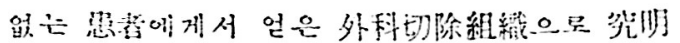
한수 있을것이다.

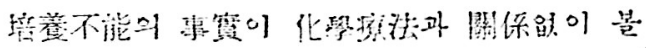

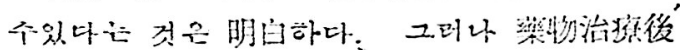




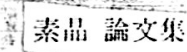

i $10=$

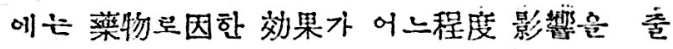

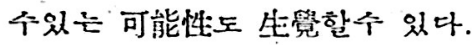

琣養不能의 結核菌을 檢出하루 있었 던 惩者 中 2 名은 手術前에 化睤療法을 받은일이 없는 患省늘인 베, 그늘의 洞巢는 㧓江化되고, 또

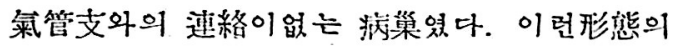
病變은 治療를 받은 患者中 比較的 發病期閒 이 짧고 氣管支와 連緮된 開放性空洞을 가진 大部分의 虫考들에게서 본 所見과는 뚜렸한 對照가 되어 있었는데, 이러한 點은 結核囷에

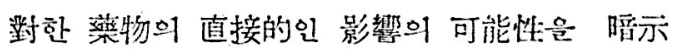
하는 것이다.

氣管支와 交通이 되어 있지않은 坬江된 結核

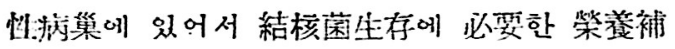

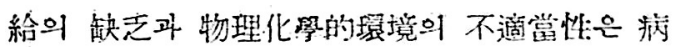
樂內結核菌死隇을 招來할수 있는 因子가되리 라그 生覺한다. 그러나 氮管支와 連絡된, 또

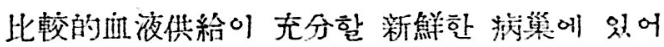
서는 化祭治療薬物과 갈은것이 重姴한 因子가

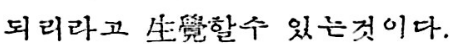

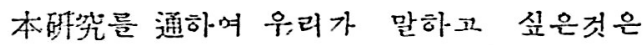

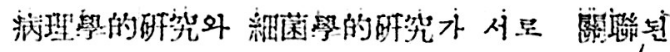

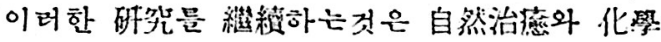
療法이 結核菌의 變質은 오게 할수있는가에 對한 比較顴祭에 必留한것이라고 말할수있다.

\section{結論}

1. 25 名思综이게서 切除한 47 個切除標本에 對하여 結核囷의 勫囷學的松查른 貿施하 였다.

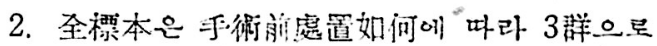

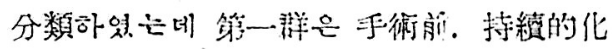
웍:㙩法은 밭았고

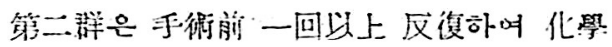

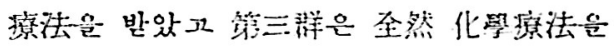
받은 일이 없다.

3. 檢查成績을 迾하며 全洋中, 一部分에 있

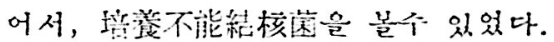

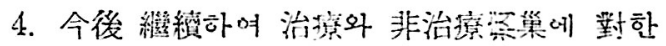

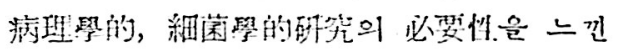
다.

\title{
The Bacteriologic Study of the Tubercle Bacilli in Resected Pulmonary Lesions
}

\author{
Kiho Kim, M. D. \\ Chest Clnic, Severance Union Medical College \\ Seoul, Korea
}

\section{INTRODUCTION}

The usage of antituberculous agents in combination with surgical resectional pro cedures in the treatment of pulmonary tuberculosis has becoming popular in the past year. However recently it has been a tendency to divert our attention from the pathologic study of the resected specimens to bacteriologic investigation. This was the common findings, in many cases in which antituberculous therapy has been done, that the lesions in resected lung specimens may contain many tubercle bacilli which do not grow on culture or produce disease in guinea pigs.

It is of great clinical importance to determine whether this phenomenon is due to natural mechanisms associated with healing or a direct result of antituberculous therapy. I have had the opportunity to study the bacteriology of the 
esions from three tuberculous patients who had had no preoperative chemotherapy. Also my present report includes he bacteriologic finding from other cases $n$ which resection was performed after arying periods of chemotherapy as well as experimental bacteriologic procedures which were carried out in connection with this relation.

\section{SUMMARY}

1. This is to present a report of becteriologic study for tubercle bacilli $r$ 47 surgical specimens fron or. witie-nts.

2. The, specimens sre devided in three groups according to preoperative ma- nagement,

The first group had certain period of chemotherapy contineously prior to surgey; the second group had several courses of chemotherapy irregularly before surgery; and third had no chemotherapy.

3. The non-culturable tubercle bacilli were found in some cases in all of the groups.

4. It may be emphasized that the furthe: correlative studies of the patiolog: and bacteriologic manifestations of both treated and untreated tuberculous lesion is nescessary. 